\title{
Developing an appropriate mathematical model for the environmental risk assessment of jack-up drilling rigs (case study: South Pars field, Iran)
}

\author{
M. Safy ${ }^{1} \cdot$ N. Moharamnejad ${ }^{1}$ A. Danehkar ${ }^{2} \cdot$ S. A. Jozi ${ }^{3}$
}

Received: 7 January 2015/Revised: 10 February 2015/Accepted: 28 February 2015/Published online: 21 April 2015

(C) Islamic Azad University (IAU) 2015

\begin{abstract}
Identifying the environmental hazards of jackup drilling rig, which is used as an exploratory drilling and offshore service platform, yet has been under intense discussion. Risk assessment along with determining the likelihood of an event occurrence and the severity of its consequences can be a useful tool for identifying the priorities and making satisfactory managerial decisions. In this study, the environmental risks attributed to jack-ups in the offshore area of Iran around the South Pars gas field were studied, and finally a new mathematical model for the environmental risk assessment in this area was presented. Due to qualitative nature of some indefinite factors, fuzzy logic was applied in this model. Moreover, the model design was tailored to the ecological and environmental conditions of South Pars gas field, and several sources of risk were aggregated for the final environmental risk assessment of jack-up drilling rig. The results indicated that the total risk calculated for jack-up in transportation was tolerable and limited management measures were required. However, for the jack-up operation risks, the site was found to be faced with "unacceptable risk" or requiring extensive management measures.
\end{abstract}

N. Moharamnejad

moharamnejad@gmail.com

1 Department of Environmental Management, Graduate School of the Environment and Energy, Science and Research Branch, Islamic Azad University, Tehran, Iran

2 Natural Resources Faculty, Department of Environmental Sciences, University of Tehran, Danesh-kadeh St., 77871-31587 Karaj, Iran

3 Department of Environment, Islamic Azad University, North Tehran Branch, 91 Mokran St., Heravi St., 1667934783 Tehran, Iran
Keywords Jack-up drilling rig · Risk assessment - Fault tree analysis (FTA) · Environmental risks · Offshore

\section{Introduction}

\section{Jack-up drilling rigs}

A jack-up drilling rig or a drilling rig consists of four main parts including hull, legs, spudcan and accessories (Vandokum 2007). The body or hull, resistant to water permeation, contains facilities, habitats, equipments, and personnel required for jack-up tasks. Jack-ups are often in either triangular or rectangular form. Those in rectangular form are often known as jack-up barges involving propulsion systems to be replaced from point to another point. These jacks are powered by diesel electric propulsion with the maximum speed of 7 knots (1 knot $=1 / 85 \mathrm{~km} / \mathrm{h}) \quad($ National Research Council 1983). There might be a floating jack-up where the necessary buoyancy force is provided to bear the weight of legs and abutments. Legs are structures made of steel with the role of keeping and bearing load in jack-up hull, lifting up the water surface, and balancing and neutralizing lateral loads. Jack-up legs might be as high as $154 \mathrm{~m}$ above sea surface in shift mode. Depending on dimensions and length of jack-up legs, they can have a significant effect on the stability of jack-up buoyancy. Jack-ups are much more flexible than jackets (Ellinas et al. 1989). Heavy weight along with a high gravity center plays a negative role in their sustainable buoyancy. Pertaining to the number of legs, in general, jack-ups are built on three or four legs, while three-legged ones are in triangular form, a variety of which has a form similar to that of the main hull. However, hull of four-legged jack-ups are generally 
in rectangular form. Jack-up and spudcan foundations can increase the surface reliance on the sea surface and reduce the acting seabed shear stress after being embedded in a site at which drilling is done by means of pneumatic, hydraulic and predominantly electrical jack-ups. A jackup drilling rig extends legs to the seabed and then lifts up the hull upward to the height so as to avoid the effects of wave and/or gain the necessary height (air gap) for drilling.

Moving rigs, when established in the site, would have high stability and capability to perform drilling operations in water and water surface to the depth of 140 and $9000 \mathrm{~m}$ respectively. To use these rigs for more depth, living quarters, helideck, derrick, crane, lifeboat and other essential supplies are installed on its surface. Jack-up drilling rigs are generally used at the depths of 15-100 m (shallow waters of the Persian Gulf). Having specific features such as buoyancy in water, allowing for individuals' accommodation and posessing drilling facilities, jack-up rigs are regarded as the facilities with a profound impact on the environment, which yet has not been taken into consideration or investigated in Iran. The prevalence of this impact implies that some of the control measures necessary for the successful deployment of a jack-up drilling unit were not in place (Hunt and Marsh 2004). As a result, the environmental risks and their corresponding effects on the susceptible marine ecosystems are neglected, underestimated, and uncontrolled, causing a lot of environmental damage and loss. Since identification of these risks is of great importance, it has been investigated in this study.

\section{Study area: South Pars gas field in southern Iran}

South Pars gas field (SPGF) is the largest gas condensate field in the world and is located in the Persian Gulf and territorial waters of Iran and Qatar. This gas field, shared between Iran and Qatar, is called North Dome field in Qatar (Fig. 1). Since the beginning, Iran and Qatar have had the same share of extraction from this field, and have competed to dominate the hydrocarbon resources of this field. The map of South Pars field is shown in Fig. 1.

In 2012, Iran extracted about 300 million cubic meters per day which was 70 million cubic meters less than Qatar. Geographical, political and economic positions across the Persian Gulf have transformed this region to one of the most important zones in the world. Furthermore, the Persian Gulf, in terms of ecology, is known as a large continental plateau rich in demersal resources, including fossil fuels such as oil and gas, and biological resources like corals, fish, crustaceans, mollusks, etc. In recent years, this area has been overshadowed by the

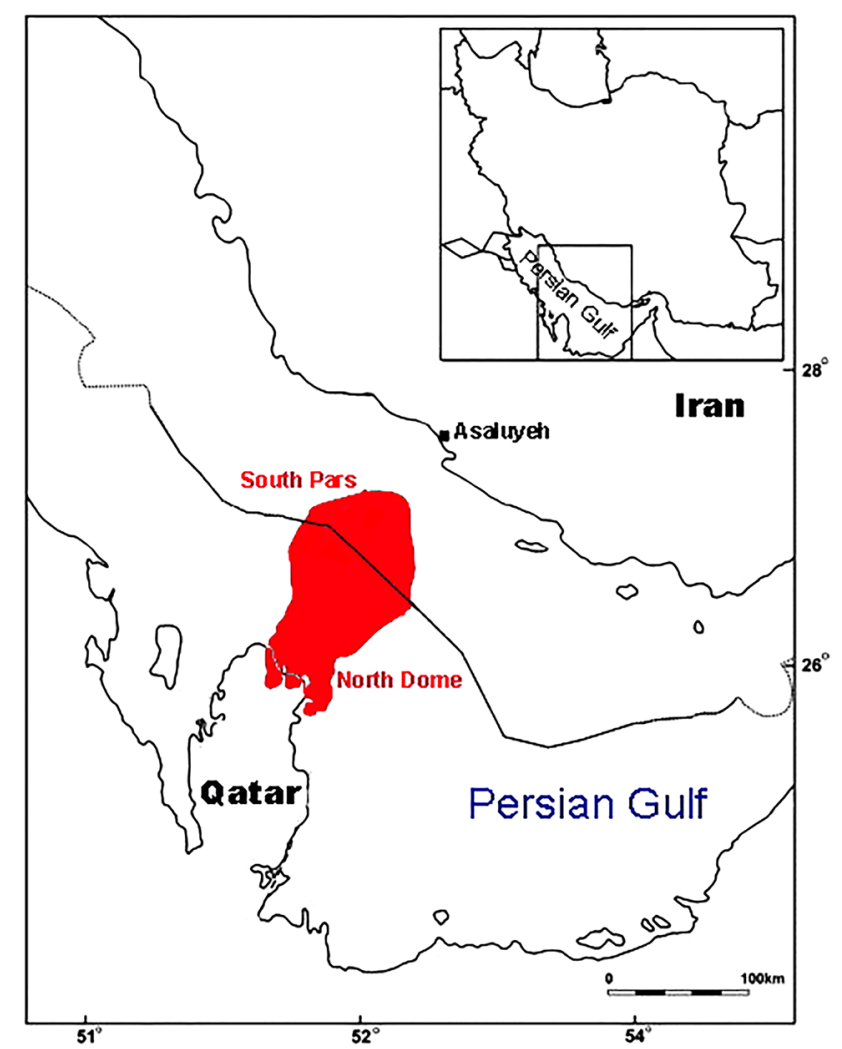

Fig. 1 Map of Iran's South Pars gas field

petroleum and chemical contaminants due to various incidences, including the Iran-Iraq War (1980) and KuwaitIraq War (1991). During the last decade, development of SPGF has been considered a priority more than before due to its huge energy reserves. Hence, the issues associated with oil exploration and gas wellbores have been taken into consideration by the environmental experts and authorities.

Contamination of aquatic ecosystems in the Persian Gulf puts the sensitive ecosystems such as coral reefs and local genetic resources in jeopardy and damages the aquatic resources such as fish and shrimp Failure to maintain the aquatic ecosystems has resulted in the extinction of sensitive species and depletion of biodiversity in the region. Since chemicals accumulate in the body of these aquatic species, they are transmitted to the higher levels of food chain by human consumption and consequently wreak havoc on human health.

Dangerous chemical contaminants in the aquatic environment include petroleum hydrocarbons and heavy metals which can have many side effects when entering the ecosystems. These contaminants either accumulate in the tissues of various aquatic organisms or cause many problems once entered the body of aquatic organisms, and ultimately penetrate into human body who uses them as food. The ecological risk has been calculated for aquatic 
life, benthic life and the food chain (Karman and Reerink 1998). The Persian Gulf has not been spared these harmful pollutants which have entered the waters and sediments, especially in coastal areas, in recent years. Petroleum hydrocarbons as the main outcome of ship traffic, discharge of ballast water, digging exploratory wells and operation of oil resumes have brought about many direct difficulties for aquatic organisms and indirect damages to the birds and human who consume these creatures through the food chain. Mass mortality of marine species such as dolphins, dugongs and sea cows, fish, turtles, and corals is considered as an environmental crisis in the Persian Gulf. This study has been carried out in South Pars field of Iran in 2014.

\section{Risk assessment}

Risk assessment defines the undesirable events or situations, determines the probability of their occurrence (HSE Case Guidelines 2014) and estimates how severe the consequences may be (Marquenie and Verburgh 1998). Several studies have been carried out on risk assessment of oil spill (Smith and Slack 2013) worldwide and different methods have been presented accordingly. In this respect, selection of an appropriate environmental risk assessment technique is considered to be an undeniable necessity (Azadeh et al. 2007). Nowadays hundreds of different methods have been introduced and developed, most of which fail to independently assess the environmental risks as they are often supplementary to each other (Jozi et al. 2012). The Oil Spill Risk Analysis (OSRA) model is considered as one of the progressive methods developed in 1975 by the Department of the Interior of the federal government of the United States of America for the impact analysis of possible oil spill from offshore oil and gas operations (Razavian et al. 2010). It is worth mentioning that the OSRA model, like most of the presented models and methods for environmental risk assessment of oil spill, is based on precise databases. However, in addition to jackup oil spill, there are other sources of pollution such as pollution from drilling mud into the sea, which can make the model more complicated. As in any kind of risk, environmental risk assessment is inherently judgmental and no analytic method can eliminate the need for judgment in it.

This research aimed to investigate the components of jack-up drilling rigs as well as their environmental risks. In this study, it was also attempted to develop an appropriate mathematical model for the risk assessment of jack-up drilling rigs.

\section{Materials and methods}

In this study, the basic definition of risk was used for the environmental risk assessment of jack-up drilling rig in transportation and in fixed position. According to this definition, the risk was calculated through multiplying the probability of occurrence by consequences severity. Firstly experts' views, brainstorming, and fieldwork on the jack-up rigs were employed to identify the environmental risks and develop a corresponding checklist. In this regard, the initial attempts were made to visit the operations and interviews on drilling operations were prepared. Then, experts' views on how to dispose wastewater by FTA method were investigated (Nouri Gharahasanlou et al. 2014; Kang et al. 2014). Finally, a method based on FTA was proposed to solve the problem (Liu et al. 2014). Moreover, FTA method was used as a strong cognitive tool to analyze the complicated systems to ensure the sufficiency of proceedings in order to avoid the possibility by which adverse outcomes might occur.

\section{Environmental hazards arising from transport of jack-ups}

In this stage, the hazards were identified to be offshore, seabed, and coastal contaminations that ultimately result in environmental destruction as well as death and migration of marine species. The related FTA is indicated in Fig. 2.

According to the observations, the most significant risks to the offshore water involved oil-fuel discharge and leakage from ballast water, equipment fires, capsized jackups, faulty leg system, and waste and wastewater discharge. Seabed contamination mainly arose from leakage and discharge of oil-fuel substances from ballast water, equipment and facilities fire, capsized rigs, and leakage because of the corrosion of systems and supplies. The environmental coastal risks resembled the offshore ones while their severity and probability varied in different spots, resulting in various risk values.

\section{Environmental hazards arising from jack-up drilling operations}

Most of the identified hazards at the operating stage held greater importance than those at the transportation stage and were associated with drilling. During the drilling operations, the major hazards involved oil and lubricants leakage and discharge, cement and drilling mud formation, fire extinguisher chemicals spill to the offshore, coastal and slightly seabed areas. $\mathrm{H}_{2} \mathrm{~S}$ leakage to aquatic media along with human waste was also accounted for. These 


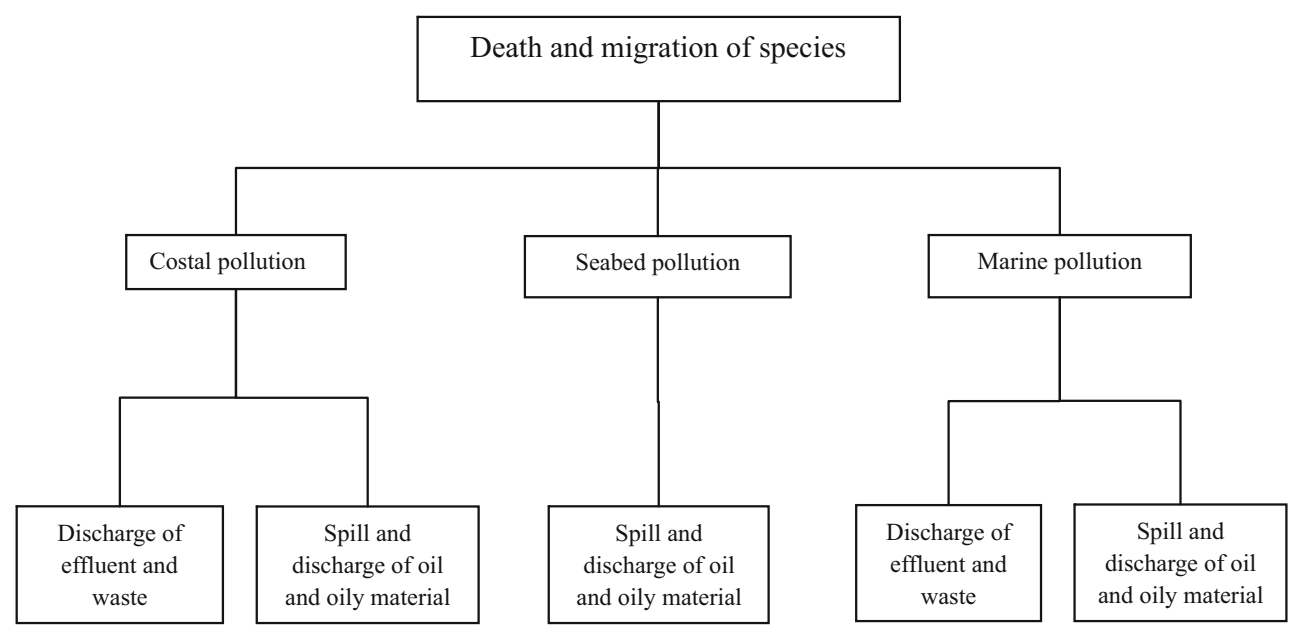

Fig. 2 First level of FTA for jack-up field transportation

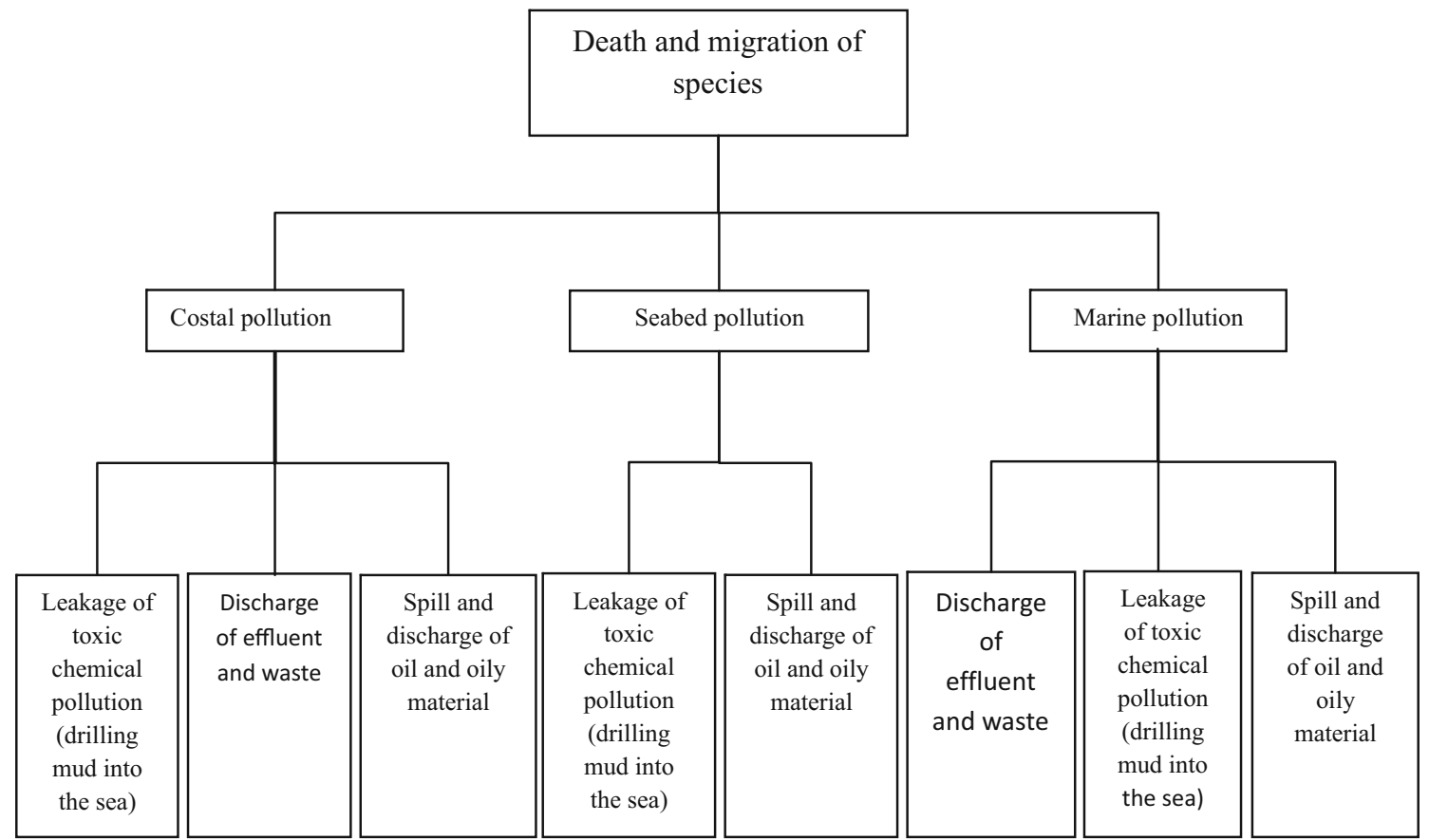

Fig. 3 First level of FTA for jack-up operation

environmental risks were similar in different areas, however, with various probability and values (Fig. 3).

To calculate the probability of pollution at each stage, the probability of occurrence of the lowest (last) level of the incidents hierarchy was determined through a checklist as: improbable (occurs once per 100 years), very low probability (occurs once per 20 years), low probability (occurs once per 10 years), medium probability (occurs once per 3 years), high probability (occurs once per 1 year), very high probability (occurs once per 6 months), and extremely probable (occurs once per month). All the
Table 1 List of identified environmental resources in the Persian Gulf

\begin{tabular}{ll}
\hline Resources & Components \\
\hline Muddy shore & Mangrove swamps \\
& Salt marshes \\
Rocky shore & Seaweed beds \\
Sandy shore & Seagrass beds \\
Coral reefs & - \\
\hline
\end{tabular}

Source IPIECA 1995-1999 
Table 2 Some of the parameters for assessment of consequences (severity database)

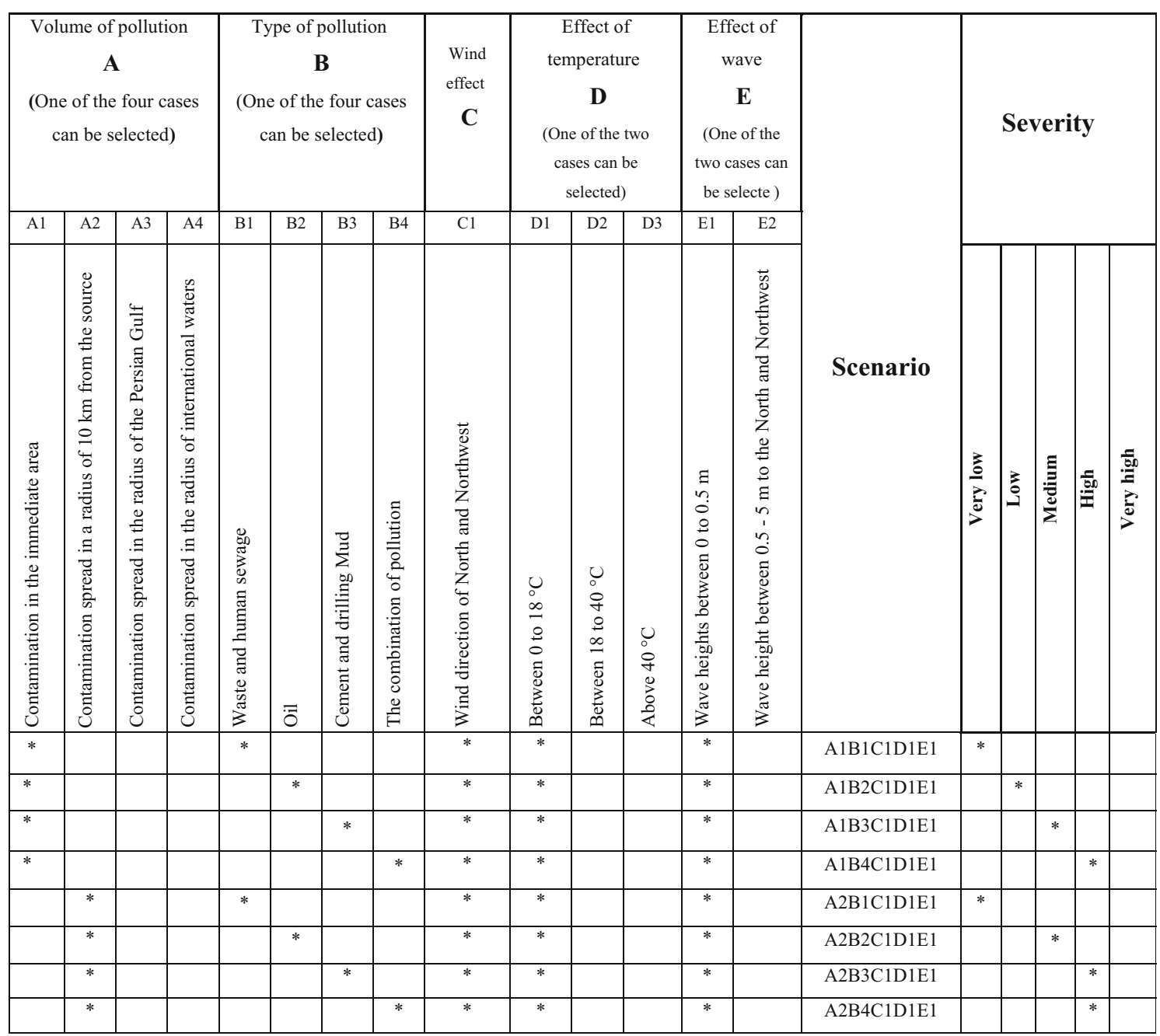

Table 3 Total risk interpretation

\begin{tabular}{lll}
\hline $\begin{array}{l}\text { Risk } \\
\text { level }\end{array}$ & Definition & Numerical range \\
\hline 1 & $\begin{array}{l}\text { Negligible risk: no certain } \\
\text { management measures are } \\
\text { required } \\
\text { Tolerable risk: limited } \\
\text { management measures are } \\
\text { required }\end{array}$ & $\begin{array}{c}\text { Minimum calculated risk; } \\
\text { product of low probability } \\
\text { of spill in low severity } \\
\text { Product of low probability of } \\
\text { pollution in low severity; } \\
\text { product of high probability } \\
\text { of pollution in high severity }\end{array}$ \\
3 & $\begin{array}{l}\text { Unacceptable risk: extensive } \\
\text { management measures are } \\
\text { required }\end{array}$ & $\begin{array}{c}\text { Product of high probability of } \\
\text { pollution in high severity; } \\
\text { maximum calculated risk }\end{array}$ \\
\hline
\end{tabular}

presented qualitative alternatives were then quantified using Triangular Fuzzy Numbers (TFN) method (Chen and Hwang 1993; Razavian et al. 2010; Jiang et al. 2012).
Table 4 Level of significance of environmental resources in the site

\begin{tabular}{lllll}
\hline $\begin{array}{l}\text { Environmental } \\
\text { resources }\end{array}$ & \multicolumn{2}{l}{ Level of significance } \\
\cline { 2 - 4 } & $\begin{array}{l}\text { Internationally } \\
\text { significant }\end{array}$ & $\begin{array}{l}\text { Regionally } \\
\text { significant }\end{array}$ & $\begin{array}{l}\text { Nationally } \\
\text { significant }\end{array}$ & $\begin{array}{l}\text { Rather } \\
\text { significant }\end{array}$ \\
\hline $\begin{array}{l}\text { Muddy shore } \\
\text { Sandy shore }\end{array}$ & $*$ & & $*$ \\
Salt marshes & $*$ & & \\
Seagrass beds & $*$ & & & \\
\hline
\end{tabular}

Then the probability of higher level incidents was calculated by incorporating the probabilities of the relevant lower level incidents. Since the number of factors (incidents) entering the equation was variable, the induction axiom was used (Lin 1981; Razavian et al. 2010). In other words, Eq. (2) was used instead of Eq. (1). 


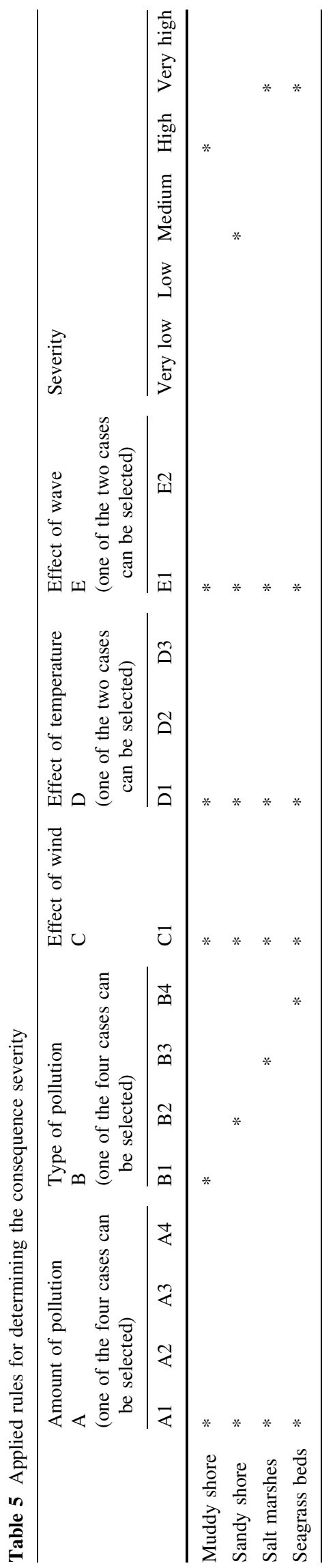

Table 6 The final results obtained

\begin{tabular}{|c|c|c|c|c|}
\hline $\begin{array}{l}\text { Environmental } \\
\text { resources }\end{array}$ & $\begin{array}{l}\text { Conseque } \\
\text { severity }\end{array}$ & & $\begin{array}{l}\text { Significance } \\
\text { factor }(S)\end{array}$ & $\begin{array}{l}\text { Probability of } \\
\text { occurrence }\end{array}$ \\
\hline Muddy shore & Medium & $*$ & $*$ & $*$ \\
\hline Sandy shore & Medium & $*$ & $*$ & $*$ \\
\hline Salt marshes & $\begin{array}{l}\text { Very } \\
\text { high }\end{array}$ & $*$ & $*$ & $*$ \\
\hline Seagrass beds & High & $*$ & $*$ & $*$ \\
\hline $\begin{array}{l}\text { Total environmental } \\
\text { risk }\end{array}$ & \multicolumn{4}{|c|}{$\begin{array}{l}\text { Jack-up field transportation } 4 / 5 \times 10^{-3} \\
\text { Jack-up field operation } 6 / 6 \times 10^{-3}\end{array}$} \\
\hline
\end{tabular}

$$
\begin{aligned}
& P(\mathrm{~A} 1 \cup \mathrm{A} 2 \cup \mathrm{A} 3 \cup \cdots \cup \mathrm{A} n-1 \cup \mathrm{A} n) \\
& =P(\mathrm{~A} 1)+P(\mathrm{~A} 2)+\cdots+P(\mathrm{~A} n-1)+P(\mathrm{~A} n) \\
& \quad-P(\mathrm{~A} 1 \cap \mathrm{A} 2)-\cdots-P(\mathrm{~A} n-1 \cap \mathrm{A} n) \\
& \quad+P(\mathrm{~A} 1 \cap \mathrm{A} 2 \cap \mathrm{A} 3)+\cdots+P(\mathrm{~A} n-2 \cap \mathrm{A} n-1 \cap \mathrm{A} n) \\
& \quad-P(\mathrm{~A} 1 \cap \mathrm{A} 2 \cap \mathrm{A} 3 \cap \mathrm{A} 4)-\cdots-P(\mathrm{~A} n-3 \cap \mathrm{A} n \\
& \quad-2 \cap \mathrm{A} n-1 \cap \mathrm{A} n)+(-1) n+1 P \\
& \quad \times(\mathrm{A} 1 \cap \mathrm{A} 2 \cap \mathrm{A} 3 \cap \cdots \cap \mathrm{A} n-1 \cap \mathrm{A} n) \\
& P(\mathrm{~A}): \text { Probability of Incident } \mathrm{A}
\end{aligned}
$$

$$
\begin{aligned}
P(\mathrm{~A} 1 \cup \mathrm{A} 2)= & P(\mathrm{~A} 1)+P(\mathrm{~A} 2)-P(\mathrm{~A} 1 \cap \mathrm{A} 2) n \\
= & 2 P(\mathrm{~A} 1 \cup \mathrm{A} 2 \cup \mathrm{A} 3 \cup \cdots \cup \mathrm{A} n-1 \cup \mathrm{A} n) \\
= & P(\mathrm{~A} 1 \cup \mathrm{A} 2 \cup \mathrm{A} 3 \cup \cdots \cup \mathrm{A} n-1) \\
& +P(\mathrm{~A} n)(1-P(\mathrm{~A} 1 \cup \mathrm{A} 2 \cup \mathrm{A} 3 \cup \cdots \cup \mathrm{A} n-1)) \\
& \forall n>2
\end{aligned}
$$

To assess the consequences severity, first the environmental resources should be categorized. In this study, the spatial environmental resources were considered and plant and animal species were studied as a part of such resources. The list of these environmental resources is presented in Table 1.

First the existing environmental resources of the region were identified and prioritized. Then the damages to each resource in the site were determined. At the next stage, the determining variables used to assess the consequences severity were identified. Since the proposed model was designed based on fuzzy logic, it was necessary to make fuzzy rules considering the mentioned variables (Moharramnejad et al. 2010). Some of the rules recommended by the experts are shown in Table 2.

The severity of environmental consequences inflicted on each environmental resource was calculated using the rules and was multiplied by the relevant significance factor of each environmental resource. The total environmental risk was calculated by Eq. (3).

Environmental Risk of Jack-up $=\Sigma P C i S i i=1$ to $n$ 
where $P$ is probability of occurrence, $C$ is consequence severity, $S$ is significance of environmental resources, and $n$ is number of damaged environmental resources.

Value of the jack-up risk was needed to be interpreted. Therefore, the final risk was defined in three levels as: negligible risk, tolerable risk, and unacceptable risk. The definition and numerical range of each risk level are given in Table 3.

The final environmental risk of jack-up drilling rig in offshore zone was the sum of different resources risk. The model presented in this study has been applied to a part of an offshore zone in SPGF. It should be noted that each incident can result in transportation and operation pollution with different probabilities.

\section{Results and discussion}

The presented model has been applied to a part of an offshore zone in South Pars felde of Iran, which contains an oil platform and several jack-up drilling rigs.

At first, a checklist was prepared and completed by experts in order to determine the probablity of incidents occurrence at the transportation and operation stages. For the severity of consequences, the mentioned site was studied to determine the present resources and the level of significance. Studies revealed muddy shores, sandy shores, sea weeds and seagrass beds as the available resouces. The resources are represented in Table 4 according to their level of significance.

The amount of pollution, type of pollution, effect of wind and effect of temperature on each environmental resource have been calculated. Since the needed management plan was found to be at the medium level, fuzzy rules were selected for this case study as expressed in Table 5 .

As can be seen in Table 6, the final results were obtained according to the information presented in the methodology.

The final environmental risk attributed to jack-up drilling rig in South Pars field of Iran was concluded to be the sum of different resources risk. As indicated in Table 6, the jack-up field transportation and operation risks in the study area are $4 / 5 \times 10^{-3}$ and $6 / 6 \times 10^{-3}$, respectively. A "tolerable risk" for Jack-up field transportation means that it requires limited management measures. However, for the jack-up field operation, the site is faced with an "unacceptable risk" implying that extensive management measures are required in this regard (Table 3).

\section{Conclusion}

Environmental pollution from jack-up drilling rigs in SPGF is one of the factors which has had many adverse impacts on aquatic ecosystems and caused irrecoverable damages to the marine environment. Considering current situation of the site and relevant requirements and standards, risk assessment process is not only capable of identifying the probable causes of accidents but also can estimate the probability of occurrence and severity of consequences. Therefore, calculation of risk assessment would assist managers and decision makers in developing and adopting proper control methods. Most of the presented models and methods for the jack-up environmental risk assessment have been developed based on precise databases. Considering the fact that in most of the regions, especially in developing countries, the aforementioned data are not easily obtained, application of these models would not be possible. Using the model presented in this study leads to rapid and accurate identification and assessment of environmental risks. In this model, based on the calculated risk, the risks with high and average values could be controlled by a proper management practices. The findings indicated that operation and transportation of jack-up drilling rigs in SPGF, despite of bearing many positive economic effects, can result in environmental risks. Majority of the hazards occurring during drilling and those occurring during jackups transportation have been reported in this study. It was found that the hazards from the operation stage, which threaten marine area in addition to causing damage to seabed and coastal ecosystems, outnumbered the hazards from jack-up transportation stage, and were mainly associated with leakage and discharge of fuel and oily materials, chemical and toxic contaminants including drilling mud, and wastewater to water. Therefore, mathematical models which simplify complex calculations could be suggested for controlling and minimizing the environmental risks in complex marine areas. Additionally, paying particular attention to international regulations and standards, such as MARPOL rules and Kuwait Convention, could play a critical role in solving the environmental problems in the Persian Gulf which is subject to pollution.

Acknowledgments The authors wish to thank all who assisted in collecting the data required for conducting this work.

\section{References}

"Health Safety and Environment Case Guidelines for Mobile Offshore Drilling Units." International Association of Drilling Contractors: USA (1 January 2014), No. 3.5, p 12

Azadeh A, Mohammad Fam I, Garakani M (2007) A Total ergonomic design approach to enhance the productivity in complicated control system. Inf Technol J 6(7):1036-1042

Chen SJ, Hwang CL (1993) Fuzzy multiple attribute decision-making, methods and applications. Springer, Berlin

Ellinas CP, Kwok R, Williams KAJ (1989) Collision Damage of Jackups. Marine Structures 2(3-5):265-279 
Hunt RJ, Marsh PD (2004) Opportunities to improve the operational and technical management of jack-up deployments. Mar Struct 17(3-4):261-273. doi:10.1016/j.marstruc.2004.08.005

Jiang W, Qu F, Zhang L (2012) Quantitative Identification and analysis on hazard sources of roof fall accident in coal mine. Procedia Eng 45:83-88. doi:10.1016/j.proeng.2012.08.125

Jozi SA, Saffarian S, Shafiee M (2012) Environment of a gas power plant exploitation unit using integrated TOP-EFMEA method. Pol J Env Stud 21(1):95-105

Kang J, Liang W, Zhang L, Lu Z, Yin W, Zang G (2014) A new risk evaluation method for oil storage tank zones based on the theory of two types of hazards. J Loss Prev Process Ind 29:267-276. doi:10.1016/j.jlp.2014.03.007

Karman CC, Reerink HG (1998) Dynamic assessment of the ecological risk of the discharge of produced water from oil and gas producing platforms. J Hazard Mater 61(1-3):43-51. doi:10.1016/S0304-3894(98)00106-X

Lin S-YT (1981) Set theory with application, 2nd edn. Mariner, England

Liu Y, Fan ZP, Yuan Y, Li H (2014) A FTA-based method for risk decision-making in emergency response. Comput Oper Res 42:49-57. doi:10.1016/j.cor.2012.08.015
Marquenie JM, Verburgh JJ (1998) Impact assessment on exploration drilling in the Wadden Sea, the Netherlands. J Hazard Mater 61(1-3):393-396. doi:10.1016/S0304-3894(98)00149-6

Moharramnejad N, Roayaii E, Lotfi F, Javid AH, Razavian F (2010) Developing an expert system and fuzzy-based model for the oil spill environmental risk assessment. J Food Agric Environ 8(2):919-923

National Research Council (1983) Drilling discharges in the marine environment. National Academy Press, Washington

Nouri Gharahasanlou A, Mokhtarei A, Khodayarei A, Ataei M (2014) Fault tree analysis of failure cause of crushing plant and mixing bed hall at Khoy cement factory in Iran. Case Stud Eng Fail Anal 2(1):33-38. doi:10.1016/j.csefa.2013.12.006

Razavian F, Moharamnejad N, Hosseinzadeh F (2010) "Introducing a new mathematical model for the stationary sources oil spill risk assessment in offshore zone (old Norouz district)." International conference on environment, Malaysia

Smith RA, Slack JR (2013) "The oil spill risk analysis model of the US Geological Survey." Geological Survey Professional Paper:1227, Bibio Gov., US

Vandokum K (2007) Ship knowledge a modern encyclopedia e-book. Dokmar, England 